\title{
PROGRESIVITAS PENGHAPUSAN PIDANA DENDA STUDY KASUS ATAS PUTUSAN MAHKAMAH AGUNG (MA) NOMOR 1554 K/PID.SUS/2015
}

\author{
Dwight Usman Motota Pakaya ${ }^{1}$ \\ 1Fakultas Hukum Universitas Indonesia \\ Corresponding Authors Email: dwight.pakaya190384@gmail.com
}

Received: February 26, 2021, Accepted: March 15, 2021 /Published: April 30, 2021 DOI: https://doi.org/10.31764/jmk.v12i1.4236

\begin{abstract}
Case No. 131/Pid.B/2013/PN.MBO. Junto case No. 201/PID/2014/PT. BNA. Junto case No. 1554 K/Pid.Sus/2015 relating to cases of sustainable forest burning. PT Kallista Alam in case No. 131/Pid.B/2013/PN.MBO. found guilty of committing an environmental crime which was carried out continuously and a fine of Rp. 3,000,000,000, - (three billion rupiah). Meanwhile, at the court of appeal in case No. 201/PID/2014/PT. BNA., The Panel of Judges upheld the District Court's decision on PT Kallista Alam. Meanwhile, the decision of the Supreme Court in case No. 1554 K/Pid.Sus/2015, the Panel of Supreme Court Justices rejected the appeal from the Cassation Petitioner / Defendant PT Kallista Alam, but did not impose a fine. The aim of the study specifically focuses on the elimination of fines by the Supreme Court of Justice. This research method is structured based on the form of juridical normative research, where juridical normative research conducts legal research by examining secondary data, the data is used as a basis for research, then the research is carried out by tracing the regulations and literature. The results of the research are expected to become a consideration for the Panel of Judges in differentiating the purpose of granting criminal sanctions and civil sanctions, where criminal sanctions have a deterrent effect on violators, while civil penalties in terms of fines so that the damage incurred can be returned to its original state and maximum sanctions should be applied to violations that have occurred. carried out in a sustainable manner.
\end{abstract}

Keywords: Case Number 1554 K/Pid.Sus/2015; Criminal Sanctions; Criminal Fine.

\section{ABSTRAK}

Perkara No. 131/Pid.B/2013/PN.MBO. Junto perkara No. 201/PID/2014/PT. BNA. Junto perkara No. 1554 K/Pid.Sus/2015 berkaitan dengan kasus pembakaran hutan yang berkelanjutan. PT Kallista Alam dalam perkara No. 131/Pid.B/2013/PN.MBO. diputus bersalah telah melakukan tindak pidana lingkungan hidup yang dilakukan secara berlanjut dan denda sebesar Rp. 3.000.000.000,- (tiga miliar rupiah). Sementara itu, pada pengadilan tingkat banding dalam perkara No. 201/ PID / 2014/ PT. BNA., Majelis Hakim menguatkan 
putusan Pengadilan Negeri atas PT Kallista Alam. Sedangkan putusan Mahkamah Agung dalam tingkat kasasi perkara No. 1554 K/Pid.Sus/2015, Majelis Hakim Agung pada amar putusannya menolak permohonan kasasi dari Pemohon Kasasi/Terdakwa PT Kallista Alam tersebut, namun tidak membebankan pidana denda. Tujuan Penelitian secara khusus menyoroti penghapusan pidana denda oleh Majelis Hakim Agung. Metode Penelitian ini disusun berdasarkan bentuk penelitian Yuridis Normatif, dimana penelitian Yuridis Normatif melakukan penelitian hukum dengan meneliti data sekunder, data tersebut digunakan sebagai bahan dasar untuk diteliti, selanjutnya penelitian dilakukan dengan menelusuri peraturan-peraturan dan literatur-literatur. Hasil penelitian diharapkan dapat menjadi pertimbangan Majelis Hakim dalam membedakan tujuan pemberian sanksi pidana dan sanksi perdata, dimana sanksi pidana bersifat memberikan efek jera bagi pelanggarnya, sedangkan perdata dalam hal denda agar kerusakan yang timbul dapat dikembalikan ke keadaan semula dan sanksi maksimal harusnya diterapkan bagi pelanggaran yang dilakukan secara berkelanjutan.

Kata kunci: Perkara No. 1554 K/Pid.Sus/2015; Sanksi Pidana; Pidana Denda.

\section{PENDAHULUAN}

Tujuan negara Indonesia sesuai Alinea ke empat Pembukaan Undang-Undang Dasar Negara Republik Indonesia (UUD NRI) 1945 adalah untuk memajukan kesejahteraan umum. Tujuan tersebut selaras dengan konsep welfare state (negara kesejahteraan), dimana dalam konsep tersebut negara diberikan wewenang untuk campur tangan dalam rangka mensejahterakan masyarakat melalui berbagai alat perlengkapan negara, pemerintah dituntut untuk bertindak aktif di tengah dinamika kehidupan masyarakat. ${ }^{1}$ Pada dasarnya, salah satu faktor kesejahteraan suatu negara dapat terlihat dari bagaimana suatu negara mengelola lingkungan hidupnya.

Awal mula Indonesia mulai terlibat dalam pengelolaan lingkungan hidup adalah dengan mengikuti Konferensi Stockholm pada tahun 19721,

1 Ridwan HR, “Hukum Administrasi Negara (Law of State Administration)," FH UII Press (2009), Ridwan HR, Hukum Administrasi Negara, Edisi Revisi, Rajawali Pers, Jakarta, 2016, hlm. 229. 


\section{Dwight Usman Motota Pakaya | Progresivitas Penghapusan Pidana Denda} Study Kasus Atas Putusan Mahkamah Agung...

dimana saat itu Indonesia mengajukan sebuah laporan yang diberi judul National Report of Indonesia, Environmental Problem in Indonesia. ${ }^{2}$ Pasca Konferensi Stockholm pemerintah mulai serius mengelola lingkungan hidup, hal tersebut dapat terlihat pada tanggal 17 Oktober tahun 1972 pemerintah mulai membentuk panitia yang mengurusi rencana kerja pemerintah terkait lingkungan hidup sebagaimana Keputusan Presiden (Keppres) Republik Indonesia No. 60 Tahun 1972 tentang Pembentukan Panitia Perumusan dan Rencana Kerja bagi Pemerintah di Bidang Pengembangan Lingkungan Hidup. ${ }^{3}$

Selanjutnya, dalam Keputusan Presiden (Keppres) Republik Indonesia No. 17 Tahun 1979 Tentang Pembubaran Panitia Perumus Dan Rencana Kerja Di Bidang Pengembangan lingkungan Hidup Dan Pengalihan Tugasnya Kepada Menteri Negara Pengawasan Pembangunan Dan Lingkungan Hidup. Dalam Keppres tersebut disebutkan bahwa untuk lebih meningkatkan penanganan masalah-masalah yang berhubungan dengan lingkungan hidup, telah diangkat Menteri Negara Pengawasan Pembangunan dan Lingkungan Hidup sebagaimana di tetapkan dalam Keputusan Presiden Republik Indonesia No. 59/M Tahun 1978 tentang Pembentukan Kabinet Pembangunan III.

Menteri Negara Pengawasan Pembangunan dan Lingkungan Hidup diangkat oleh Presiden Soeharto kala itu untuk mengambil alih semua tugas dari Panitia Perumus dan Rencana Kerja bagi Pemerintah di bidang Pengembangan Lingkungan Hidup. Keseriusan pemerintah penyelenggaraan pemerintahan, terutama dalam mengelola lingkungan hidup begitu penting, karena tanpa penyelenggaraan pemerintahan yang

\footnotetext{
2 Richard Sunday Thlakma and John Eche Omale, "AN ASSESSMENT OF THE VARIOUS MITIGATION STRATEGIES TO COMBAT DESERTIFICATION IN JIBIA AND KAITA LOCAL GOVERNMENT AREAS OF KATSINA STATE," Geosfera Indonesia (2019).

3 Siti Sundari Rangkuti, "Hukum Lingkungan Dan Kebijaksanaan Lingkungan Nasional," Airlangga Universityt Press, Edisi Ketiga, (Surabaya: Airlangga University Press, 2005), hlm. 64.
} 


\section{Dwight Usman Motota Pakaya | Progresivitas Penghapusan Pidana Denda} Study Kasus Atas Putusan Mahkamah Agung...

baik, sulit mengharapkan akan adanya pengelolaan lingkungan hidup yang baik. ${ }^{4}$

Selanjutnya, pada tahun 1992 dengan disepakatinya KTT Bumi di Rio de janiero, diharapkan membawa harapan baru bagi lingkungan hidup dengan dicanangkannya pembangungan berkelanjutan atau sustainable development. Esensi pembangunan berkelanjutan disebut triangle of sustainability yang meliputi tiga aspek yaitu; ecology, economy, dan social security. Jika pembangunan hanya berpihak pada aspek sosial dan ekonomi maka pembangunan tersebut dikatakan tidak berkelanjutan. Pembangunan berkelanjutan harus memperhatikan ketersediaan sumber daya alam yang ada dan digunakan untuk kebutuhan jangka panjang.

Sementara itu, mulai terjadi pergeseran prinsip dari prinsip good governance menjadi prinsip good environmental governance, hal tersebut dikarenakan isu-isu terkait lingkungan hidup telah menjadi pusat perhatian. Di Indonesia, sumber daya alam malah dieksploitasi besarbesaran, malah semakin menjadi-jadi, tingkat kerusakan makin mengkhawatirkan. Keadaan tersebut seharusnya menyadarkan kita, terutama pemerintah dalam tata kelola pemerintahannya, agar good environmental governance dapat terwujud.

Perjalanan politik hukum terkait lingkungan di Indonesia dimulai dengan pembentukan Undang-Undang (UU) Nomor 4 tahun 1982 tentang Ketentuan-Ketentuan Pokok Lingkungan Hidup. Sementara itu, UndangUndang Dasar 1945 telah mengamanatkan untuk mendayagunakan sumber daya alam yang ada, demi untuk memajukan kesejahteraan umum dan untuk mencapai kebahagiaan hidup berdasarkan Pancasila, perlu dilaksanakan pembangunan berkelanjutan yang berwawasan

\footnotetext{
4 A. Sonny Keraf, Etika Lingkungan, Jakarta: Penerbit KOMPAS, 2006, hlm. 201.
} 


\section{Dwight Usman Motota Pakaya | Progresivitas Penghapusan Pidana Denda}

Study Kasus Atas Putusan Mahkamah Agung...

lingkungan hidup berdasarkan kebijaksanaan nasional yang terpadu dan menyeluruh dengan memperhitungkan kebutuhan generasi masa kini dan generasi masa depan, dibentuklah Undang-undang Nomor 23 Tahun 1997 tentang Pengelolaan Lingkungan Hidup (UU PLH). ${ }^{5}$

UU PLH kemudian direvisi lagi menjadi Undang-Undang No. 32 Tahun 2009 tentang Perlindungan Dan Pengelolaan Lingkungan Hidup (UU PPLH). Selama kurun 12 tahun, Negara kita melewati masa transisi dari pemerintahan Orde Baru ke pemerintahan reformasi. 6 UU PPLH merupakan reformasi dalam bidang perlindungan lingkungan hidup, yang merupakan jawaban atas penegakan hukum lingkungan yang lebih baik, karena dari segi substansialnya ${ }^{7}$ masih banyak hal-hal kiranya dapat menghambat penegakan hukum lingkungan. Berdasarkan hal tersebut, dipandang perlu untuk dilakukan perbaikan terhadap Undang-undang Pengelolaan Lingkungan Hidup yang berlaku sebelumnya yaitu Undangundang No. 23 Tahun 1997 tentang Pengelolaan Lingkungan Hidup.

UU PPLH pada dasarnya telah menganut prinsip tata kelola pemerintahan yang baik, yang menguatkan prinsip-prinsip perlindungan dan pengelolaan lingkungan hidup yang baik. Hal ini dikarenakan setiap perumusan dan instrumen pencegahan pencemaran dan/atau kerusakan lingkungan hidup serta penanggulangan dan penegakan hukum mengharuskan adanya pengintegrasian aspek partisipasi, transparansi, akuntabilitas, dan keadilan di dalamnya. ${ }^{8}$ Pemerintah perlu memaksimalkan program, agar kerusakan yang terjadi pada lingkungan

5 Pemerintah Republik Indonesia, “Undang Undang Nomor 23 Tahun 1997 Tentang Pengelolaan Lingkungan Hidup," Lembaran Negara Republik Indonesia 1997 No. 68, TLN No. 3699 (1997).

6 Marhaeni Ria Siombo, Hukum Lingkungan dan Pelaksanaan Pembangunan Berkelanjutan di Indonesia, (Jakarta: PT Gramedia Pustaka Utama, 2012), hlm. 79

7 Kementerian Negara Lingkungan Hidup, Naskah Akademis Rancangan Undang-Undang tentang Pengelolaan Lingkungan Hidup, Jakarta, 2009, hlm. 1.

8 Suphia, "TENTANG PERLINDUNGAN DAN PENGELOLAAN LINGKUNGAN HIDUP ( $\begin{array}{lllllll}\text { UUPPLH )," JURNAL RECHTENS 2, no. } & 1 & \text { (2013): 74-75, }\end{array}$ http:/ / ejurnal.uij.ac.id/index.php/REC/article/view/79/75. 


\section{Dwight Usman Motota Pakaya | Progresivitas Penghapusan Pidana Denda}

Study Kasus Atas Putusan Mahkamah Agung...

dapat berkurang. Sebagaimana amanat UUPPLH Nomor 23 tahun 1997, yang diperbarui dengan UUPPLH no 32 tahun 2009. Undang-undang tersebut diharapkan dapat berjalan sesuai dengan keadaan saat ini dan akan mendatang. Tetapi implementasi Undang-Undang tersebut masih saja menimbulkan pelanggaran di masyarakat. Hal ini menjadi faktor tidak berjalannya peraturan yang ada karena kurangnya kesadaran pihakpihak terkait, tentang pentingnya menjaga kelestarian alam dan lingkungan, sehingga aspek pemidanaan dianggap sebagai salah satu jalan keluar terhadap penegakan hukum lingkungan. ${ }^{9}$

Perkara No. 131/Pid.B/2013/PN.MBO. Junto No. 201/ PID / 2014/ PT. BNA. Junto No. 1554 K/Pid.Sus/2015 berkaitan dengan kasus pembakaran hutan yang berkelanjutan yang dilakukan oleh PT Kallista Alam. Penegakan hukum pidana, dalam hal ini yang terkait dengan lingkungan hidup, pada prakteknya tidak berfungsi dengan baik dalam hal perbaikan lingkungan yang terkena dampaknya, yang dapat berjalan efektif hanya faktor penjaranya (deterrant factor). Oleh karena itu, dalam prakteknya hukum pidana selalu dilakukan secara selektif. ${ }^{10}$

Dalam kasus PT Kallista Alam karena sifatnya berkelanjutan, pelaku pencemaran dan/atau perusak lingkungan harus dijatuhi sanksi pidana yang maksimal, hal tersebut bertujuan untuk menyelamatkan lingkungan hidup yang dihuni oleh masyarakat. Pada dasarnya, tujuan dari hukum pidana dalam hal ini termasuk pidana lingkungan hidup ialah: (1) mencegah terjadinya kejahatan atau perbuatan yang tidak dikehendaki atau perbuatan yang salah, dan (2) mengenakan penderitaan atau pembalasan yang setimpal atau layak kepada si pelaku. ${ }^{11}$

9 Eric Rahmanul Hakim, "Penegakan Hukum Lingkungan Indonesia Dalam Aspek Kepidanaan," Media Keadilan: Jurnal Ilmu Hukum 11, no. 1 (2020): 43, http://journal.ummat.ac.id/index.php/JMK/article/view/1615.

10 Sukanda Husin, Penegakan Hukum Lingkungan Indonesia, Cet. 1, Ed. 1 (Jakarta: Sinar Grafika, 2009), hlm. 92-93.

11 Ibid, hlm. 121-122. 


\section{Dwight Usman Motota Pakaya | Progresivitas Penghapusan Pidana Denda Study Kasus Atas Putusan Mahkamah Agung...}

Ultimum remedium atau upaya hukum terakhir terhadap pelaku pencemaran dan/atau perusak lingkungan diisyaratkan dalam UU PPLH. Penjatuhan pidana penjara atau denda kepada pelaku pencemaran dan/atau perusakan lingkungan hidup melalui instrument pidana tersebut, pada dasarnya dilakukan dan ditujukan untuk menjatuhkan pidana penjara atau denda kepada pelaku pencemaran dan/atau perusakan lingkungan hidup, namun dalam perkara PT Kallista Alam, Majelis Hakim Mahkamah Agung menghapus pidana denda bagi PT Kallista Alam.

\section{METODOLOGI}

Salah satu cara ilmiah dalam memperoleh data adalah melalui suatu metode penelitian, yang selanjutnya dipergunakan untuk tujuan serta kegunaan tertentu. ${ }^{12}$ Metode Penelitian pada artikel disusun berdasarkan bentuk penelitian Yuridis Normatif, yaitu suatu cara yang dipergunakan untuk melakukan penelitian hukum dengan meneliti data sekunder, data tersebut digunakan sebagai bahan dasar untuk diteliti, penelitian dilakukan dengan menelusuri peraturan-peraturan dan literaturliteratur, ${ }^{13}$ dalam hal ini terkait dengan perkara PT Kallista Alam, menggunakan data sekunder. Sementara itu, penelitian studi Pustaka dipergunakan untuk mengumpulkan data dalam penelitian ini. ${ }^{14}$ Studi Pustaka yaitu dengan melakukan penelusuran literatur untuk memahami konseptualitas hukum dalam sumber hukum. Data sekunder dalam penelitian ini terdiri dari bahan hukum primer yaitu UUD NRI 1945, berbagai peraturan perundang-undang dan putusan, bahan hukum sekunder seperti hasil karya tertulis seperti buku, karya tulis ilmiah,

\footnotetext{
12 Sugiyono, Metode Penelitian Kombinasi, (Bandung: Alfabeta, 2015), hal. 3.

13 Soerjono Soekanto dan Sri Mamudji, Penelitian Hukum Normatif (Suatu Tinjauan Singkat), (Jakarta: Rajawali Pers, 2001), hlm. 13-14.

14 Ibid, hal. 21.
} 
makalah maupun artikel, serta bahan hukum tersier meliputi ini kamus hukum dan Kamus Besar Bahasa Indonesia.

\section{PEMBAHASAN}

\section{A. Perkara Nomor 131/Pid.B/2013/PN.MBO}

Perkara No. 131/Pid.B/2013/PN.MBO. Junto No. 201/ PID / 2014/

PT. BNA. Junto No. 1554 K/Pid.Sus/2015 adalah perkara terkait Pidana Lingkungan Hidup, dimana Sdr. Subianto Rusdi (Direktur PT Kallista Alam) mewakili terdakwa PT Kallista Alam.

Adapun dakwaan dari Jaksa antara lain, PT. Kalista Alam di Kecamatan Meulaboh telah membuka lahan dengan cara membakar yang dilakukan secara berlanjut, yaitu diantaranya pada hari Jum'at tanggal 23 Maret 2012 sekira pukul 07:30 WIB sampai dengan hari Selasa tanggal 27 Maret 2012 sekira pukul 05:00 WIB dan pada hari Minggu tanggal 17 Juni 2012 sampai dengan hari minggu tanggal 24 Juni 2012 atau setidaktidaknya pada suatu waktu dalam tahun 2012 bertempat di Areal Pekebunan PT. Kalista Alam.

Adapun tuntutan Jaksa/Penuntut Umum antara lain:

- Menyatakan terdakwa yaitu PT.Kalista Alam yang diwakili oleh Sdr. Subianto Rusid (Direktur PT.Kalista Alam), terbukti sebagaimana Pasal 69 ayat (1) huruf (h) telah melakukan pembakaran 2 lahan, dimana pembakaran tersebut dilakukan secara terus menerus/berlanjut sebagaimana diatur pasal 64 ayat (1) KUH Pidana dan diancam pidana dalam Pasal 108 jo Pasal 69 ayat (1) huruf (h), Pasal 116 ayat (1) huruf (a), Pasal 118, Pasal 119 Undang-undang No. 32 tahun 2009 tentang perlindungan dan Pengelolaan Lingkungan Hidup;

- Menjatuhkan pidana terhadap terdakwa PT.Kalista Alam yang diwakili oleh Sdr. Subianto Rusid (Direktur PT.Kalista Alam) dengan pidana denda sebesar Rp.3.000.000.000,- (tiga milyar) rupiah;

Selanjutnya, amar putusan ${ }^{15}$ perkara No. 131/Pid.B/2013/PN.MBO antara lain sebagai berikut:

15 Putusan Pengadilan Negeri Meulaboh No. 131/Pid.B/2013/PN/Mbo., hlm. 150. 
- Menyatakan perbuatan terdakwa PT.KALLISTA ALAM telah terbukti secara sah dan meyakinkan bersalah melakukan tindak pidana "LINGKUNGAN HIDUP YANG DILAKUKAN SECARA BERLANJUT".

- Menjatuhkan pidana terhadap Terdakwa PT KALLISTA ALAM oleh karena itu dengan pidana denda sebesar Rp. 3.000.000.000,- (tiga miliar rupiah);

Walaupun PT Kallista Alam telah dijatuhi hukuman bersalah atas kerusakan lingkungan hidup yang dilakukan secara terus menerus/berlanjut, putusan tersebut masih dianggap kurang maksimal, karena tidak menimbulkan efek jera bagi para pelakunya. Tuntutan dari Jaksa yang hanya menuntut terdakwa dengan denda sebesar Rp 3.000.000.0000,- (tiga milyar rupiah) tersebut, untuk suatu korporasi merupakan hal yang ringan, apalagi tindakan pembakaran lahan tersebut terbukti selalu berulang, dimana setiap tahun selalu terjadi kasus pembakaran hutan yang biasanya dilakukan oleh suatu korporasi.

\section{B. Perkara Nomor 201/ PID / 2014/ PT. BNA}

Adapun amar putusan perkara No. 201/ PID / 2014/ PT. BNA. ${ }^{16}$ antara lain:

- Menyatakan terdakwa PT Kalista Alam telah terbukti secara sah dan meyakinkan bersalah " MELAKUKAN TINDAK PIDANA MEMBUKA LAHAN UNTUK PERKEBUNAN KELAPA SAWIT DENGAN CARA MERUSAK LINGKUNGAN SECARA BERLANJUT “.

- Menjatuhkan pidana terhadap terdakwa oleh karena itu dengan pidana denda sebesar Rp 3.000.000.000,- (tiga miliar) rupiah.

- Menguatkan putusan Pengadilan Negeri Meulaboh tanggal 15 Juli 2014 No. 131/Pod.B/2013/PN Mbo untuk selebihnya.

Majelis Hakim Pengadilan Tinggi atas putusan Pengadilan Negeri Meulaboh tanggal 15 Juli 2014 No. 131/Pod.B/2013/PN Mbo pada dasarnya bersifat menguatkan, walaupun ada perbaikan amar putusan

\footnotetext{
16 Putusan Pengadilan Tinggi Banda Aceh No. 201/ PID / 2014/ PT. BNA., hlm. 27-28.
} 


\section{Dwight Usman Motota Pakaya | Progresivitas Penghapusan Pidana Denda} Study Kasus Atas Putusan Mahkamah Agung...

terkait dengan klasifikasi tindak pidana yang dijatuhkan kepada Terdakwa.

\section{Perkara Nomor 1554 K/Pid.Sus/2015}

Adapun amar putusan Majelis Hakim perkara No. 1554 K/Pid.Sus/2015 17 antara lain sebagai berikut:

- Menolak permohonan kasasi dari Pemohon Kasasi/Terdakwa: PT. KALLISTA ALAM tersebut;

- Membebankan kepada Terdakwa untuk membayar biaya perkara pada tingkat kasasi ini sebesar Rp2.500,00 (dua ribu lima ratus rupiah);

Dalam putusannya, denda sebesar Rp 3.000.000.000,- (tiga miliar rupiah) yang diputus pada pengadilan tingkat pertama dan tingkat banding, oleh Majelis Hakim tingkat kasasi dihapuskan. Padahal untuk suatu korporasi besar, denda senilai Rp 3.000.000.000,- (tiga miliar rupiah) tidak sebanding dengan kerusakan yang telah ditimbulkan.

\section{D.Progresivitas putusan Majelis Hakim dalam Perkara Nomor 1554}

\section{K/Pid.Sus/2015}

Menurut Black's Law Dictionary, sanction (sanksi) adalah "a penalty or coercive measure that results from failure to comply with a law, rule, or order (a sanction for discovery abuse)"18 dengan kata lain dapat diartikan sebagai sebuah hukuman atau tindakan memaksa yang dihasilkan dari kegagalan untuk mematuhi undang-undang. ${ }^{19}$

Sementara itu, terkait persepsi yang muncul dalam suatu bangsa atas hak asasi manusia, pemidanaan pada hakekatnya merupakan hal yang penting yang masuk dalam sanksi pidana, karena nilai-nilai sosial budaya suatu bangsa juga tercermin dari pemidanaannya, dimana hal tersebut

\footnotetext{
17 Putusan Mahkamah Agung No. 1554 K/Pid.Sus/2015., hlm. 58.

18 Black's Law Dictionary, 8th (USA, 2004), page. 4177.

${ }^{19}$ Kemendikbud, “KBBI - Kamus Besar Bahasa Indonesia," Kamus Besar Bahasa Indonesia Balai Fustaka, Jakarta, (2019), hlm. 1265.
} 


\section{Dwight Usman Motota Pakaya | Progresivitas Penghapusan Pidana Denda}

Study Kasus Atas Putusan Mahkamah Agung...

terlihat dari bentuk teori pembenaran pidana yang ada, juga dalam bentuk kebijakan pemerintah dipandang sangat penting. ${ }^{20}$

Tindakan Majelis Hakim dalam perkara No. 1554 K/Pid.Sus/2015 yang menghapuskan denda sebesar Rp 3.000.000.000,- (tiga miliar) tersebut, merupakan kemunduran dalam penegakan hukum di Indonesia, khususnya terkait dengan penegakan pidana di bidang lingkungan, karena Hakim yang progresif pada dasarnya akan menggunakan hukum yang terbaik, walaupun keadaan saat itu merupakan keadaan yang paling buruk. $^{21}$

Apa yang dilakukan oleh Majelis Hakim perkara tersebut bukanlah putusan yang dikategorikan sebagai putusan yang progresif, karena bertentangan dengan nilai kepastian, keadilan dan kemanfaatan hukum sebagai syarat suatu putusan dapat dikatakan progresif. Aparatur penegak hukum, terutama Hakim menurut Prof. Dr. Satjipto Rahardjo hendaknya tidak terpaku dan terbelenggu dengan positivisme hukum, karena telah terbukti selama ini banyak terjadi ketidakadilan khususnya kepada pencari keadilan.

\section{E. Pertimbangan Majelis Hakim Mahkamah Agung Perkara Nomor 1554}

K/Pid.Sus/2015 yang dalam Putusannya Menghapus Denda bagi PT

\section{Kallista Alam}

Dalam pertimbangan hukum Majelis Hakim perkara No. 1554 K/Pid.Sus/2015, telah terjadi kerugian negara untuk biaya pemulihan rehabilitasi lahan guna memfungsikan kembali ekologi yang rusak sebesar Rp366.098.669.000,00 (tiga ratus enam puluh enam miliar sembilan puluh delapan juta enam ratus enam puluh sembilan ribu rupiah), dimana PT. Kallista Alam selaku pihak yang menyebabkan terjadinya kebakaran.

${ }^{20}$ Muladi dan Barda Nawawi Arief, 1998, Teori-Teori dan Kebijakan Pidana, Bandung: Alumni, hlm.5.

21 Satjipto Rahardjo, 2006, Membedah Hukum Progresif, Jakarta: Kompas, hlm. 56. 


\section{Dwight Usman Motota Pakaya | Progresivitas Penghapusan Pidana Denda}

Study Kasus Atas Putusan Mahkamah Agung...

Berdasarkan hal tersebut, dalam perkara perdata No. 651 K/PDT/2015 yang berhubungan dengan perkara a quo, kerugian negara yang terjadi telah dibebankan dalam putusannya, sehingga tidak dibebankan kembali. Putusan Majelis Hakim Mahkamah Agung tersebut seharusnya mempertimbangkan perbedaan dari tujuan pemberian sanksi pidana dan sanksi perdata, dimana sanksi pidana bersifat memberikan efek jera bagi pelanggarnya, oleh karena sanksi maksimal harusnya diterapkan bagi pelanggaran yang dilakukan secara berkelanjutan.

Pada ketentuan hukum pidana, dikenal kaidah hukum restitutif. Tujuan kaidah restitutif yang utama pada dasarnya agar kerusakan yang terjadi akibat dilanggarnya kaidah dalam hukum, dapat dikembalikan seperti keadaan semula sebelum terjadi kerusakan yang ditimbulkan. ${ }^{22}$ Dalam perkara terkait lingkungan, penerapan kaidah hukum restutif seharusnya didahulukan oleh Majelis Hakim, karena pidana denda seharusnya ditujukan untuk pengembalian kepada keadaan semula atas kerusakan lingkungan yang ditimbulkan.

\section{SIMPULAN}

Putusan Majelis Hakim tingkat pertama perkara No. 131/Pid.B/2013/PN.MBO. jo putusan tingkat banding perkara No. 201/PID/2014/PT. BNA. telah tepat apabila didasarkan pada ultimum remedium atau pemidanaan dengan hukuman maksimal. Namun pada tingkat kasasi dalam perkara No. 1554 K/Pid.Sus/2015, Majelis Hakim Mahkamah Agung malah menghapuskan pidana denda maksimal yang diberikan kepada PT Kallista Alam. Putusan Majelis Hakim Mahkamah Agung bukanlah putusan yang didasarkan pada hukum progresif yang berkembang di masyarakat, putusan tersebut terbelenggu oleh pemikiran

22 Suadamara Ananda, “Tentang Kaidah Hukum,” Jurnal Hukum Pro Justitia, Vol. 26 No. 1 (Januari 2018), hlm. 78, https://journal.unpar.ac.id/index.php/projustitia/article/view/1110. 


\section{Dwight Usman Motota Pakaya | Progresivitas Penghapusan Pidana Denda}

Study Kasus Atas Putusan Mahkamah Agung...

positivistis dan legal analytical. Selanjutnya Putusan pidana No. 1554 K/Pid.Sus/2015 ancaman pidana yang ditimbulkan kurang menimbulkan efek jera, apalagi Majelis Hakim Mahkamah Agung menghapus pidana denda tanpa mempertimbangkan perbedaan dari tujuan pemberian sanksi pidana dan sanksi perdata, dimana sanksi pidana bersifat memberikan efek jera bagi pelanggarnya, padahal kasus pembakaran lahan yang dilakukan PT. Kallista Alam sifatnya berkelanjutan dan sudah banyak menimbulkan permasalahan lingkungan hidup. Eksekusi putusan juga belum jadi perhatian yang serius dalam prakteknya, karena pidana denda seharusnya benar-benar dipergunakan untuk pemulihan kepada keadaan semula, jadi bukan hanya sekedar masuk dalam keuangan negara saja.

\section{DAFTAR PUSTAKA}

Ananda, Suadamara. “Tentang Kaidah Hukum.” Jurnal Hukum Pro Justitia, 2006.

https://journal.unpar.ac.id/index.php/projustitia/article/view/111 0 .

A. Sonny Keraf, Etika Lingkungan, Jakarta: Penerbit KOMPAS, 2006, hlm. 201.

Black's Law Dictionary, 8th (USA, 2004), page. 4177.

Hakim, Eric Rahmanul. "Penegakan Hukum Lingkungan Indonesia Dalam Aspek Kepidanaan." Media Keadilan: Jurnal Ilmu Hukum 11, no. 1 (2020):

43.

http://journal.ummat.ac.id/index.php/JMK/article/view/1615.

Kemendikbud. "KBBI - Kamus Besar Bahasa Indonesia." Kamus Besar Bahasa Indonesia (2019).

Kementerian Negara Lingkungan Hidup, Naskah Akademis Rancangan Undang-Undang tentang Pengelolaan Lingkungan Hidup, Jakarta, 2009, hlm. 1. 


\section{Dwight Usman Motota Pakaya | Progresivitas Penghapusan Pidana Denda}

Study Kasus Atas Putusan Mahkamah Agung...

Marhaeni Ria Siombo, Hukum Lingkungan dan Pelaksanaan Pembangunan Berkelanjutan di Indonesia, (Jakarta: PT Gramedia Pustaka Utama, 2012), hlm. 79.

Muladi dan Barda Nawawi Arief, 1998, Teori-Teori dan Kebijakan Pidana, Bandung: Alumni, hlm.5.

Pemerintah Republik Indonesia. “Undang Undang Nomor 23 Tahun 1997

Tentang Pengelolaan Lingkungan Hidup." Lembaran Negara Republik Indonesia 1997 (1997). No. 68, TLN No. 3699.

Rahardjo Satjipto, 2006, Membedah Hukum Progresif, Jakarta: Kompas, hlm. 56.

Rangkuti, Siti Sundari. "Hukum Lingkungan Dan Kebijaksanaan Lingkungan Nasional." Airlangga Universityt Press (1996), Edisi Ketiga, (Surabaya: Airlangga University Press, 2005), hlm. 64.

Richard Sunday Thlakma and John Eche Omale, "AN ASSESSMENT OF THE VARIOUS MITIGATION STRATEGIES TO COMBAT DESERTIFICATION IN JIBIA AND KAITA LOCAL GOVERNMENT AREAS OF KATSINA STATE," Geosfera Indonesia (2019).

Ridwan HR. 2016 "Hukum Administrasi Negara (Law of State Administration)." FH UII Press (2009) Edisi Revisi, Rajawali Pers, Jakarta, , hlm. 229.

Siombo, Marhaeni Ria. “TANGGUNG JAWAB PEMDA TERHADAP KERUSAKAN LINGKUNGAN HIDUP KAITANNYA DENGAN KEWENANGAN PERIZINAN DI BIDANG KEHUTANAN DAN PERTAMBANGAN." Jurnal Dinamika Hukum (2014).

Soekanto Soerjono dan Mamudji Sri, Penelitian Hukum Normatif (Suatu Tinjauan Singkat), (Jakarta: Rajawali Pers, 2001), hlm. 13-14.

Sugiyono, Metode Penelitian Kombinasi, (Bandung: Alfabeta, 2015), hal. 3. Sukanda Husin, Penegakan Hukum Lingkungan Indonesia, Cet. 1, Ed. 1 (Jakarta: Sinar Grafika, 2009), hlm. 92-93. 
Dwight Usman Motota Pakaya | Progresivitas Penghapusan Pidana Denda Study Kasus Atas Putusan Mahkamah Agung...

Suphia. “TENTANG PERLINDUNGAN DAN PENGELOLAAN LINGKUNGAN HIDUP ( UUPPLH )." JURNAL RECHTENS 2, no. 1 (2013):

72-89.

http:/ / ejurnal.uij.ac.id/index.php/REC/article/view/79/75.

Thlakma, Richard Sunday, and John Eche Omale. "AN ASSESSMENT OF THE VARIOUS MITIGATION STRATEGIES TO COMBAT DESERTIFICATION IN JIBIA AND KAITA LOCAL GOVERNMENT AREAS OF KATSINA STATE." Geosfera Indonesia (2019).

Putusan Pengadilan Negeri Meulaboh No. 131/Pid.B/2013/PN/Mbo.

Putusan Pengadilan Tinggi Banda Aceh No. 201/ PID / 2014/ PT. BNA. Putusan Mahkamah Agung No. 1554 K/Pid.Sus/2015. 